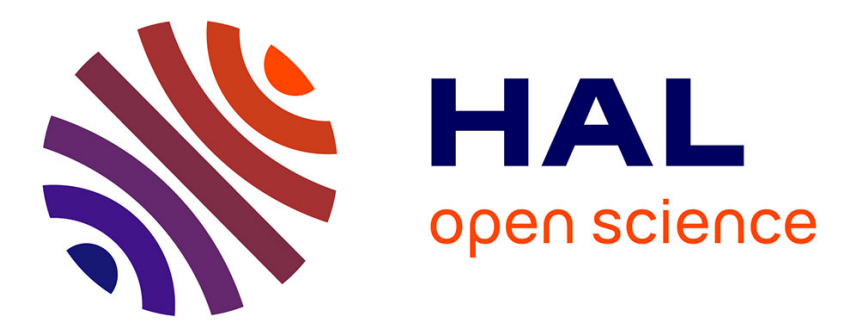

\title{
Numerical analysis of soil liquefaction induced failure of embankments
}

\author{
Stefania Gobbi, Fernando Lopez-caballero, Davide Forcellini
}

\section{To cite this version:}

Stefania Gobbi, Fernando Lopez-caballero, Davide Forcellini. Numerical analysis of soil liquefaction induced failure of embankments. 6th International Conference on Computational Methods in Structural Dynamics and Earthquake Engineering, COMPDYN 2017, Jun 2017, Rhodes Island, Greece. pp.990-1006, 10.7712/120117.5471.17027 . hal-02457302

\section{HAL Id: hal-02457302 \\ https://hal-centralesupelec.archives-ouvertes.fr/hal-02457302}

Submitted on 16 Apr 2021

HAL is a multi-disciplinary open access archive for the deposit and dissemination of scientific research documents, whether they are published or not. The documents may come from teaching and research institutions in France or abroad, or from public or private research centers.
L'archive ouverte pluridisciplinaire HAL, est destinée au dépôt et à la diffusion de documents scientifiques de niveau recherche, publiés ou non, émanant des établissements d'enseignement et de recherche français ou étrangers, des laboratoires publics ou privés. 


\title{
NUMERICAL ANALYSIS OF SOIL LIQUEFACTION INDUCED FAILURE OF EMBANKMENTS
}

\author{
Stefania Gobbi ${ }^{1}$, Fernando Lopez-Caballero ${ }^{2}$, Davide Forcellini ${ }^{1}$ \\ ${ }^{1}$ Universit di San Marino \\ Via Salita alla rocca 44 \\ stefania.gobbi,davide.forcellini@unirsm.sm \\ ${ }^{2}$ Laboratoire MSS-Mat CNRS UMR 8579, Centrale Supelec \\ Grande Voie des Vignes 92295, Chatenay-Malabry, France \\ fernando.lopez-caballero@centralesupelec.fr
}

Keywords: Earthquake engineering, Liquefaction, Numerical modelling, Embankment.

\begin{abstract}
Soil structures such as river dikes, highway embankments, and earth dams have been frequently damaged during past major earthquakes. In most cases, large deformations occurred due to liquefaction of the supporting loose cohesionless foundation soil, resulting in cracks, settlement, lateral spreading, and slumping. Some researchers showed that river levees resting on non-liquefiable foundation soil have been damaged. In this regard, the base of such levees subsided in a bowl shape due to foundation consolidation that was shown to have the principal contribution to liquefaction as an underlying mechanism. This paper aims at describing the global dynamic response of a thin Loose Sand layer located buried in deep $(10 \mathrm{~m})$ stratum of Clay (less permeable), situated at the foundation of a levee, due to liquefaction phenomenon. This study purpose is to reproduce such behavior by applying numerical simulations, adopting the open-source computational platform OpenSees. In particular, this study considers a $2 D$ soil model of a levee subjected to earthquakes in order to investigate the failure of embankments induced by non-liquefiable soil foundation with a thin sand layer with partially drained condition. A parametric analysis using ground motions at multiple levels of intensity was performed to highlight the influence of parameters such as, the thickness of saturated zone, the permeability ratio between saturated zone and non-liquefiable soil (i.e. drain condition) on the obtained crest settlement and on the induced damage level of the embankment.
\end{abstract}




\section{Introduction}

Past earthquakes confirm that the major cause of severe damages to earth embankments is the liquefaction of the soil foundation. In particular, it is known that river levees over soft soil are the most susceptible to the liquefaction of the foundation and the crest settlement can be larger than half of the embankment height [18]. However, it has been reported that levees resting on nonliquefiable foundation have been severely damaged if the foundation is highly compressibly, such as thick soft clay and peat deposits. Fig.1 illustrates this unknown mechanism. First, in absence of earthquake, the levee is subjected to consolidation and settlement due to the softness of the clay foundation; then, the part of the levee that subsides, becomes submerged in the ground water table and the subside part becomes looser and liquefiable by an unkown procedure.

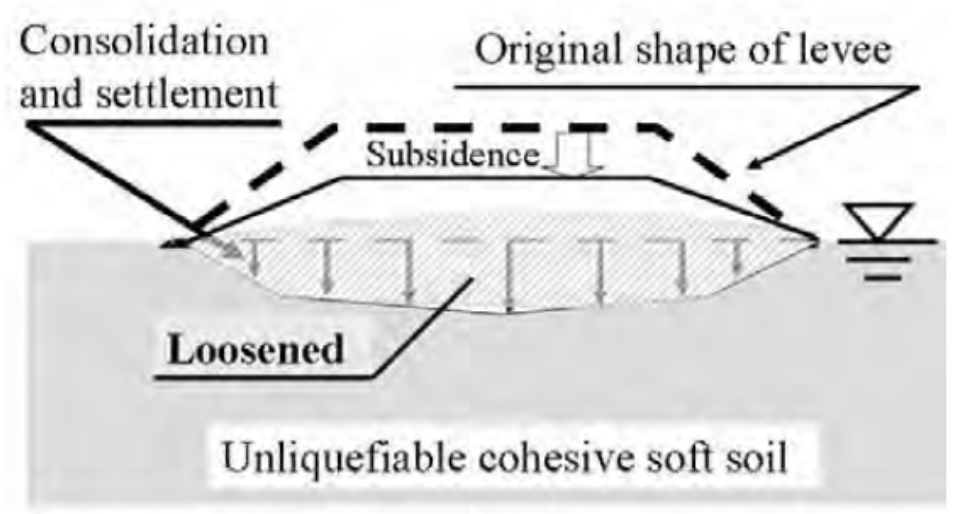

Figure 1: Mechanism of liquefaction in river levee after consolidation settlement in foundation.

In 1993, the Kushiro embankment system was damaged during the Kushiro-Oki earthquake [24]. This episode was very singular because some of the damaged levee were over nonliquefiable peat deposits. In this context, it has been reported that the highly compressible and less permeable layer below the levee had subsided in a concave shape, creating a satured zone [24]. In addition, more recently, a considerable number of river levees were damaged with the same mechanism by the 2011 Pacific Coast of Tohoku Earthquakes [17], it means that the analysis of countermeasure for this new failure mechanism will be consider with a new approach. The present study aims at describing the global dynamic response of a thin Loose Sand layer located buried in deep $(10 \mathrm{~m})$ stratum of Clay (less permeable), situated at the foundation of a levee, due to liquefaction phenomenon. Thus seismic effect, in the engineering practice had not been consider as a problem, but recent events have shown that in reality the problem exist [19, 17]. Fisrt, the liquefaction effects on the section profile of the center line of the system levee-foundation is evaluated. In this scope, the dynamic response of a Loose Sand layer located between two layers of Clay after the consolidation is simulated. Firstly, the section profile of the center line of the dam is subjected to a set of earthquakes in order to take into account the effect of the seismic hazard. In this regard, parametric studies are conducted for the soil column referring to the permeability ratio between saturated zone and non-liquefiable soil (i.e. drain condition), the liquefaction vulnerability of soil on the characteristics of the input ground motion and the influence of the thickness of the satured zone on the liquefactioninduced failure. Then, the dynamic analysis of levee-type model is investigated, focusing on 
the earthquake induced failure response and the influence of drainage conditions and the liquefiable layer thickness on the collapse path is examined. The levee has been modeled with 9-4 node plane-strain finite elements (FE) with the OpenSees (Open System for Earthquake Engineering Simulation, Mazzoni et al. [16]) framework, GiD (version 13.0, [23]) has been used for pre and post processing. Numerical analyses have been performed with non-linear material models, in particular, PressureDependMultiYield02 and PressureIndependMultiYield materials $[22,21,28]$ were implemented in order to simulate the soil behavior. In the first section, the numerical model is presented. Thereafter, the dynamic analysis and the effect of liquefaction is presented for the section profile of the center of the dam and then of the entire system of the embankment.

\section{Numerical Model}

\subsection{Geometry}

The model is composed of different types of materials (Fig, 2). For the levee, a $9 \mathrm{~m}$ of Dense Sand is implemented, while under the embankement, there is a $10 \mathrm{~m}$ of Clay and inside it, there is a thin layer of Loose Sand of $1 \mathrm{~m}$ (layer liquefiable). The groundwater table is located at the surface. The embankment slope inclination is equal to 3:1 (vertical:horizontal). The dimensions of the model and its geometry are presented in Fig. 2. An elastic half-space bedrock underlies the entire soil profile with a shear-wave velocity $V_{s}$ equal to $700 \mathrm{~m} / \mathrm{s}$.

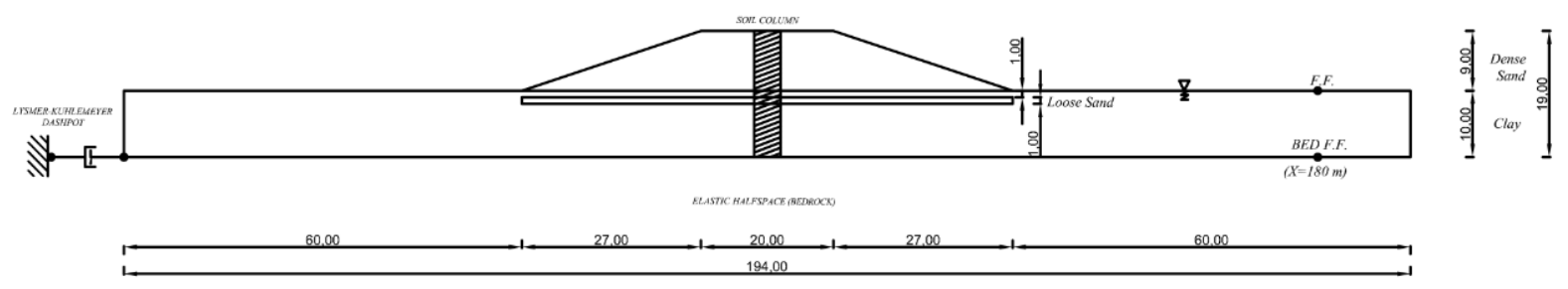

Figure 2: Geometry of the model levee.

\subsection{Finite Element Model}

The soil is assumed to be horizontally homogeneous and a $2 \mathrm{D} \mathrm{u}-p_{w}$ coupled finite element computation with plane-strain assumption was performed. OpenSees (Open System for Earthquake Engineering Simulation, Mazzoni et al. [16]) framework was adopted, following the previous research contributions Elgamal et al. [4] and Tonni et al. [27]. The mesh is composed by the 9-4 QuadUP elements, which are able to simulate fluid-solid coupling in order to consider the effective stress analysis. In particular, for these elements, the corner nodes have three degrees of freedom, two translational and one pore pressure, and the interior nodes have only two translational degrees of freedom $\left(U_{x}, U_{y}\right)$. The thickness of the element is $0.5 \mathrm{~m}$ that it was chosen in order to prevent numerical dispersion. The nodes at the base are fixed against vertical translation in accordance with the assumption that the soil layers are underlain by bedrock. In order to simulate the dry condition above the groundwater table, pore pressure nodes are fixed against the pore pressure. Periodic boundary conditions are assumed for the nodes that are at the same vertical location in order to obtain equal deformations foundation. To account for the finite rigidity of the underlying half-space, a Lysmer and Kuhlemeyer [14] dashpot is incorporated at the base of the soil column using a zeroLength element and the viscous uniaxial material. The 
system is excited at the base by a horizontal force time history which is proportional to the known velocity time history of the ground motion. The saturated soil system is based upon the Biot theory for porous media. A simplified numerical formulation of this theory, known as $\mathrm{u}-p_{w}$ formulation (Zienkiewicz and Shiomi [29]), was implemented numerically [22, 21, 28]. The so-called $\mathrm{u}-p_{w}$ formulation, consists of neglecting fluid acceleration terms and its convective terms of this acceleration so that the unknown variables remain the displacement of the solid $u$ and the pressure of the water $p_{w}$.

An implicit Newmark numerical integration scheme is used in the dynamic analysis for the discretization in time with a time step equal to $\Delta t=10^{-3} \mathrm{~s}$ with a numerical damping equal to $\xi=0.2 \%$. In fact, since the model consider elastoplastic soil behavior, there is inherent hysteretic damping which occurs, however, a small amount of Rayleigh damping is used so there is still some damping at low strain values. In addition, a non-dissipative set of Newmark parameters is also used, with $\gamma=0.5$ and $\beta=0.25$.

\subsection{Soil Constituve Model}

The soil constitutive model (Figure3) implemented in OpenSees ([21], [5]) is based on the multisurface-plasticity theory for cyclic hysteretic response proposed by Prevost [22]. In this context, the phenomenological interaction between shear and volumetric response (contraction or dilation) is typically handled by specifying an appropriate non-associative flow rule (e.g.Prevost [22], Dafalias [3]).

Figure 3 shows the response behaviour of a saturated undrained cohesionless soil. Depending on the relative location of the stress state with respect to the phase transformation (PT) surface [10, 12], different expressions for the volumetric component $P$ " were specified [21]. The main modelling parameters include typical dynamic soil properties such as low-strain shear modulus and friction angle, as well as calibration constants to control pore-pressure buildup rate, dilation tendency, and the level of liquefaction-induced cyclic shear strain.

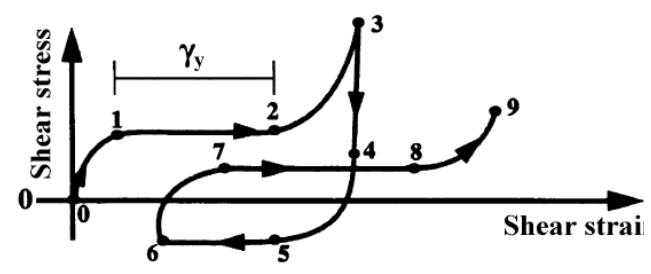

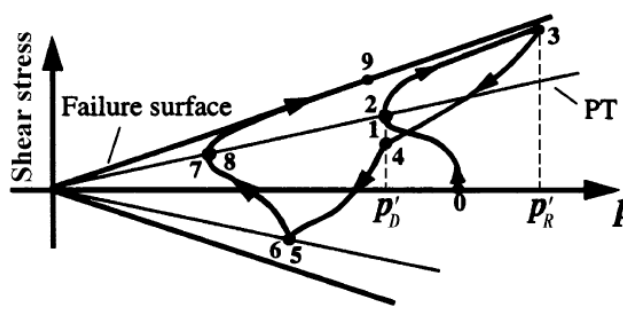

(a)

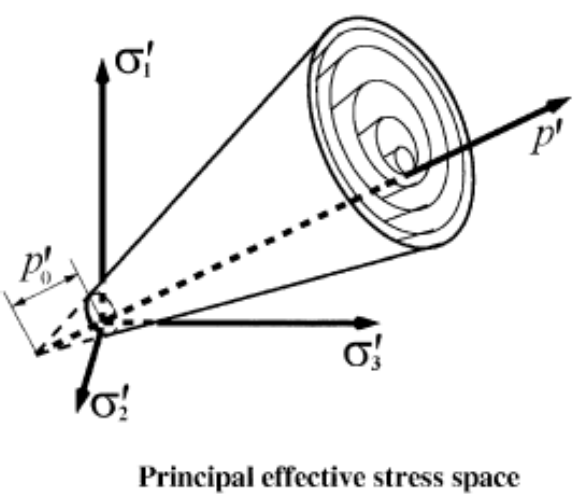

(b)

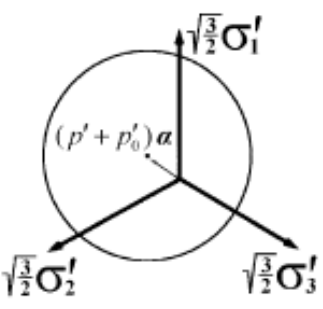

Deviatoric plane

Figure 3: a)Schematic of constitutive model response showing shear stress, effective confinement, and shear strain relationship, b)Conical yield surface in principal stress space and deviatoric plane (after Prevost [22], Parra [21], Yang and Elgamal [28]). 


\subsection{Material Properties}

The soil constitutive behavior is modeled using the PressureDependMultiYield02 Material and the PressureIndependMultiYield Material. The saturated sand layers are based on the Nevada sand properties [6]. The main modeling parameters are summarized in Table1.

\begin{tabular}{cccc}
\hline Parameters & Dense Sand & Loose Sand & Clay \\
\hline Mass Density $\rho$ & $2100 \mathrm{~kg} / \mathrm{m}^{3}$ & $1840 \mathrm{~kg} / \mathrm{m}^{3}$ & $1500 \mathrm{~kg} / \mathrm{m}^{3}$ \\
Low-strain shear modulus $G_{r}$ & $135.0 \mathrm{MPa}$ & $90.0 \mathrm{MPa}$ & $60.0 \mathrm{MPa}$ \\
Friction angle $\phi$ & $36.5^{\star}$ & $32^{\star}$ & 0 \\
Contraction parameter $c_{1}$ & 0.013 & 0.067 & - \\
PT angle $\phi_{P T}$ & $26^{\star}$ & $26^{\star}$ & - \\
Dilatation parameter $d_{1}$ & 0.3 & 0.06 & - \\
Porodity $\eta$ & 0.354 & 0.435 & 0.4 \\
Permeability $K_{s}$ & $1.0 \cdot 10^{-4} \mathrm{~m} / \mathrm{s}$ & $1.0 \cdot 10^{-4} \mathrm{~m} / \mathrm{s}$ & $1.0 \cdot 10^{-10}$ \\
Bulk Modulus $u_{b} u l k$ & $5.0 \cdot 10^{-6} \mathrm{kPa}$ & $5.2 \cdot 10^{6} \mathrm{kPa}$ & $5.3 \cdot 10^{5}$ \\
Cohesione $c$ & - & - & $37 \mathrm{kPa}$ \\
\hline
\end{tabular}

Table 1: Soil Model Parameters

\section{Dynamic Response of the Soil Column}

\subsection{Influence of the Drainage Condition}

Liquefaction is related to soil permeability as permeable soils can dissipate rapidly the excess pore water and liquefaction phenomenon may be less extended or prevented. In this section, five differents values of permebility of the Clay layer, are used for the parametric analysis. In particular, the value of $K_{s}$ varies from $1.0 \cdot 10^{-10}$ to $1.0 \cdot 10^{-5} \mathrm{~m} / \mathrm{s}$. Figure 4 illustrates the time evolution of pore water pressure for the different values of permeability at $10.5 \mathrm{~m}$ below the surface (in the middle of the Loose Sand layer), it shows that the build up of excess pore water pressure depends of the permeability ratio between saturated zone and non-liquefiable soil and the dissipation is produced more rapidly when soil permeability is greater. In the Fig. 4 is reported the pore pressure ratio $r_{u}$ (i.e. computed as the ratio of excess pore pressure to initial effective vertical stress) at the end of the shaking in function of the soil permeability. It is interesting to note that only when the $r_{u}$ reaches a value greater than 0.8 , the liquefaction occurs.

\subsection{Influence of the earthquake's characteristics}

The buildup of excess pore pressure depends on many factors concerning the soil as well as the input motion. Several studies have underlined the importance of the choise of the seismic signal in case of non linear soil behaviour of soil model. In this study, a wide range of input motion (real and synthetic) has been selected to study the liquefaction vulnerability of soil of the input ground motion. The earthquake signals were proposed by Iervolino and Cornell [8], Sorrentino et al. [26]. Thus, 183 unscaled records were chosen from the Pacific Earthquake Engineering Research Center (PEER) database. Their magnitude range between 4.9 and 7.9 and their site-to-source distance from 1 to $200 \mathrm{~km}$. All these earthquake were chosen with a great variety in their characteristics in order to analyse their influence on the liquefaction triggering. 


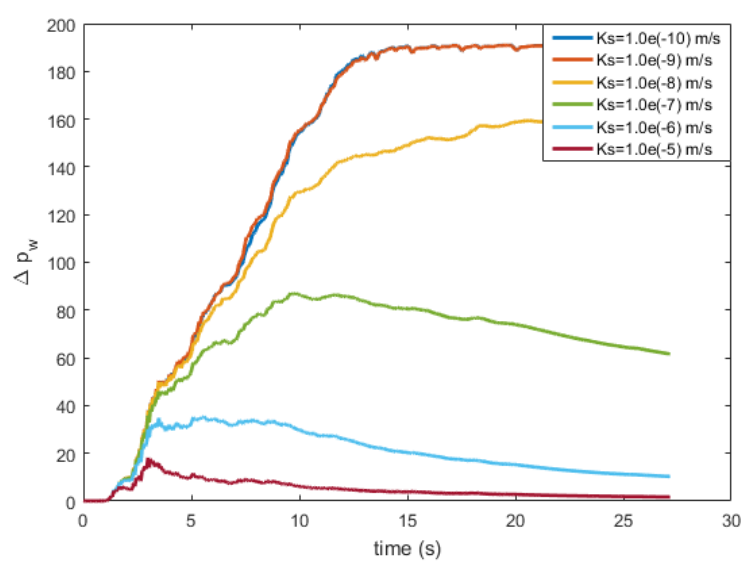

(a)

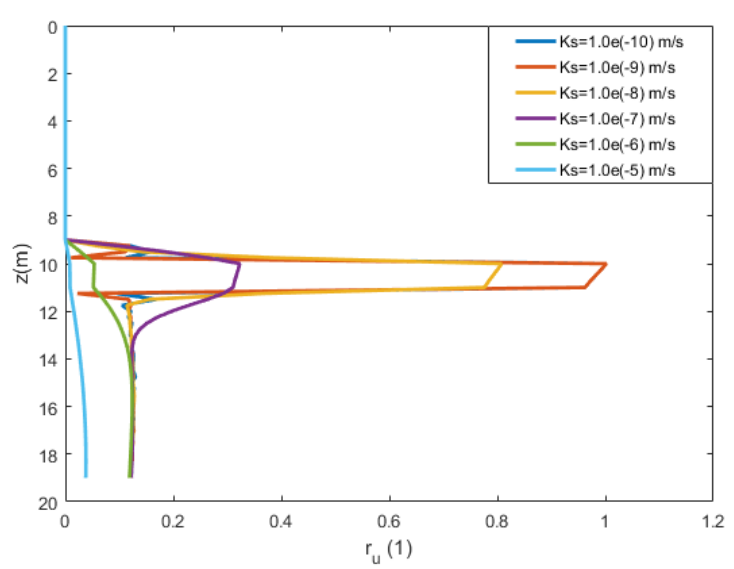

(b)

Figure 4: a) Excess pore water pressure and b) Pore pressure ratio at the end of the shaking at $10.5 \mathrm{~m}$ (in the middle of the liquefiable layer) as a function of the permeability of the layer of Clay.

Figure 5 shows the response spectra with a $5 \%$ structural damping of all the input earthquake motions.

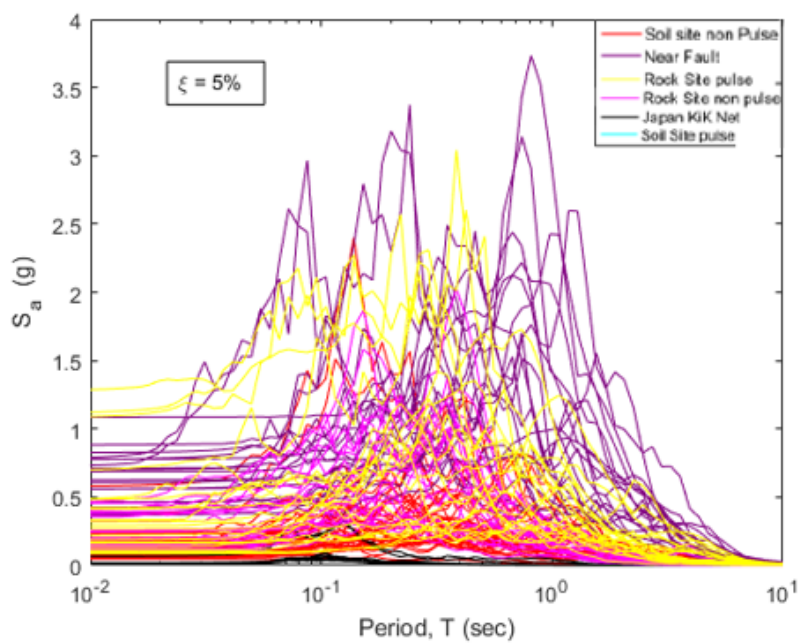

(a)

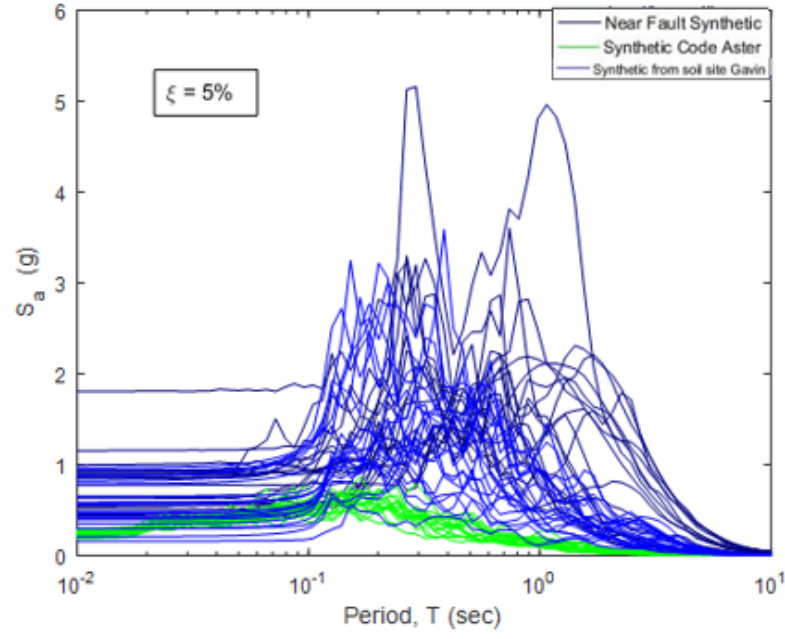

(b)

Figure 5: Acceleration response spectra of input motions (a)Real and b)Synthetic).

In the context of the liquefaction evaluation in the soil deposit, the liquefaction index (Q) will be used to compare the different analyses. This index is computed as [25]:

$$
Q_{H}=\frac{1}{H_{2}} \int_{0}^{H_{2}} r_{u, e n d}(z) d z
$$

where $r_{u, e n d}$ is the liquefaction ratio evaluated at the end of the ground motion, $H_{2}$ is the thickness of the liquefiable layer. 
Figure 6 shows the results of the analyses performed on the soil column as a function of the period of equivalent harmonic wave $\left(T_{V / A}=\alpha \cdot P G V / P G A\right)$. It illustrates if the application of ground motion cause the liquefaction in the Loose Sand layer (if $r_{u}>0.8$ ). In particular, the points filled are sign of liquefaction and the others means that liquefaction is not occured. In terms of earthquake-induced liquefaction, results match the trend of the classification proposed by Cameron and Green [2] and Kawase [11], in fact the points filled follow the direction of increasing velocity from the right-down corner towards the left-up one. The index Q gives information about the total liquefied area and when it is equal to unity, it means that liquefaction is present throughout the thickness of the liquefiable layer $\mathrm{H}_{2}$. Figure 6 shows that for the soil column, the highest level of liquefaction is found for PGV higher than $50 \mathrm{~cm} / \mathrm{s}$ and PGA $\geq$ $0.4 \mathrm{~g}$. In addition, it is interesting the fact that when the value $1 / T_{V / A}$ is similar to the frequence of the soil profile $\left(f_{p}=2.25 \mathrm{~Hz}\right)$, the liquefaction ratio is higher than the other earthquakes close to these but with the differents frequency contents.

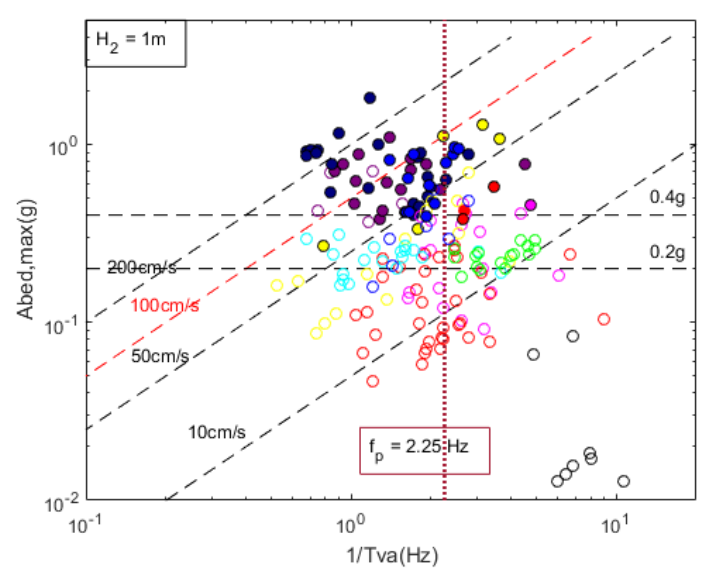

(a)

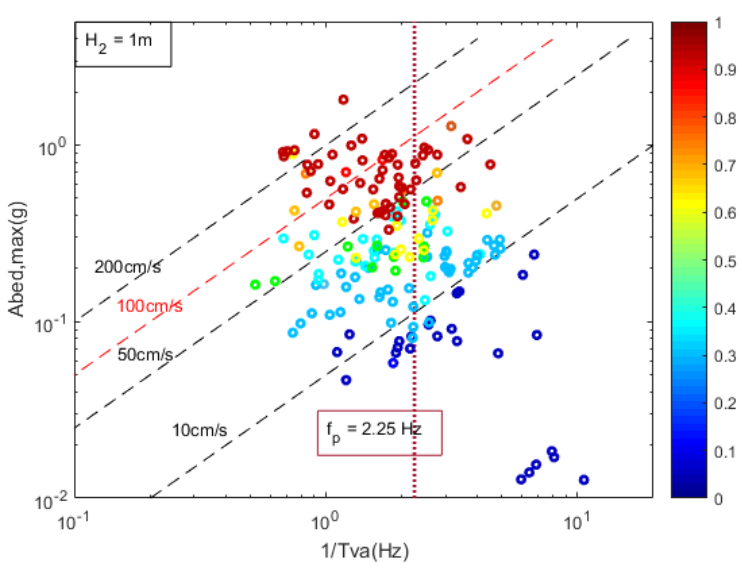

(b)

Figure 6: a)Comparison of the severity of all ground motion with $H_{2}=1 \mathrm{~m}$, b)Relation between PGA, $T_{V / A}$ and liquefaction index (Q) for soil column with $H_{2}=1 \mathrm{~m}$

\subsection{Influence of the thickness of the liquefiable layer}

Then, a parametric analysis using ground motions at multiple levels of intensity (Figure 5) was performed in order to highlight the influence of the thickness of saturated zone $\left(\mathrm{H}_{2}\right)$. Ishihara [9] investigated the effect that the thickness of liquefiable soil $\left(\mathrm{H}_{2}\right)$ and non-liquefiable surface layer $\left(H_{1}\right)$ have on liquefaction ground failure (mainly sand boiling) on the ground surface. According to this theory, the occurrence of sand boiling depends on the relation of $H_{1}$ to $\mathrm{H}_{2}$ and $a_{\text {bed,max }}$. Therefore, the soil column is modeled with a thickness of the satured zone (the Loose Sand layer) that varies from $1 \mathrm{~m}$ to $8 \mathrm{~m}$. The differents models of the column are reported in Figure 7 . 


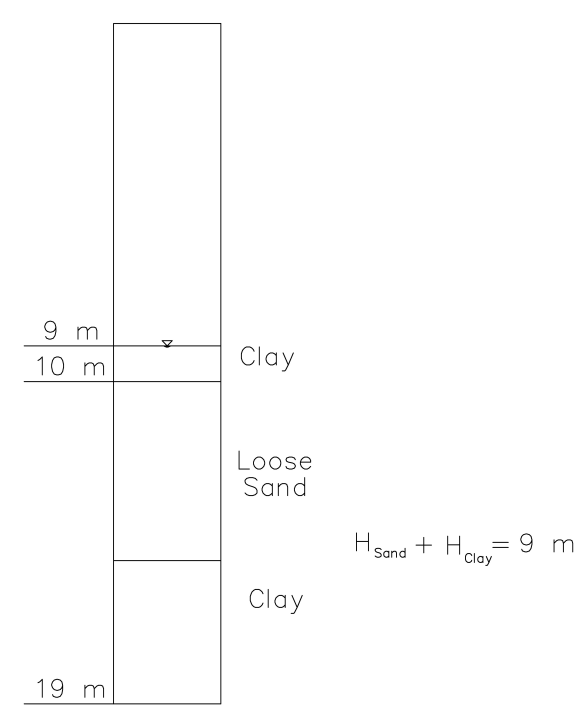

Figure 7: Models of the soil column with a thickness of the liquefied layer that varies from $1 \mathrm{~m}$ to $8 \mathrm{~m}$.

Results reported in Fig. 8 confirm the trend proposed before, according to which the severity of the motions follows the direction of increasing velocity from the right-down corner towards the left-up one. Following this, increasing the thickness of the liquefiable soil layer, the number of motions in the upper left part of the diagram, that are caused of liquefaction-induced ground damages, increases.

In addition, in the Figures 8, horizontal dashed lines indicate a costant acceleration of $0.2 \mathrm{~g}$ and $0.4 \mathrm{~g}$ in order to compare the results obtained with the guidelines curves of Ishihara [9]. In this regard, most of the motions with $a_{\max }<0.4 \mathrm{~g}$ do not have $r_{u}>0.8$ in the Loose Sand layer and increasing the thickness of this layer, results confirm that the number of the motions, under these lines, are more dangerous in terms of liquefaction-induced ground failure. In addition results show that earthquakes with an equivalent period $T_{V / A}$ similar to the fundamental period of the soil column, are more dangerous in terms of liquefaction-induced ground damages than others. In fact increasing the thickness $\mathrm{H}_{2}$, Figure 8 shows that the number of earthquakes that caused liquefaction in this zone is greater. 


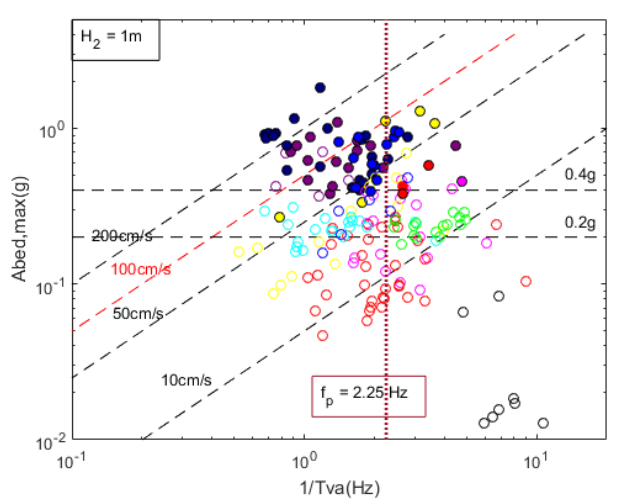

(a) $H_{2}=1 \mathrm{~m}$.

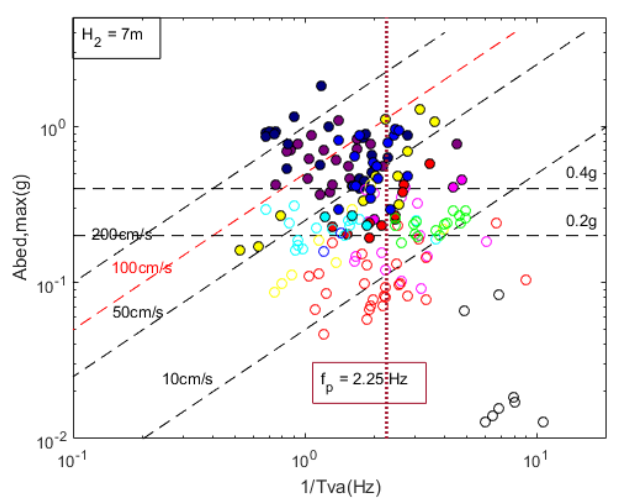

(c) $H_{2}=7 m$.

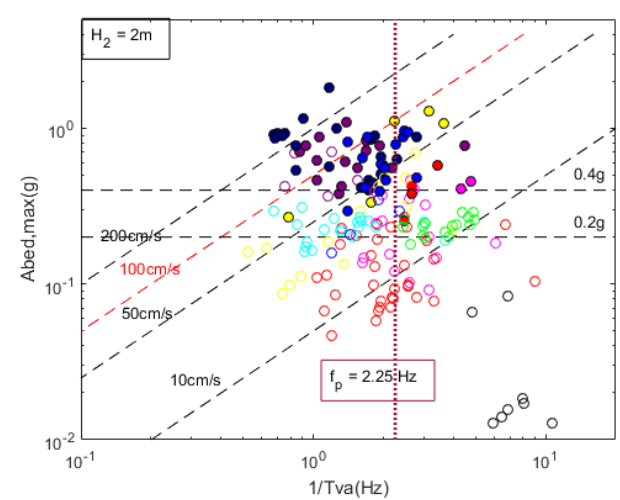

(b) $H_{2}=2 m$.

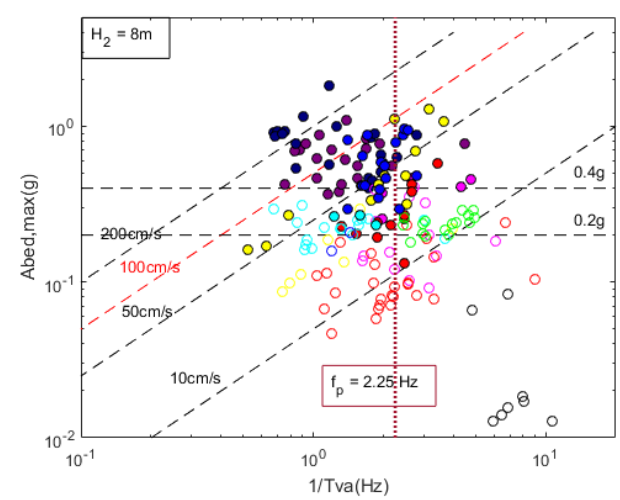

(d) $H_{2}=8 m$.

Figure 8: Comparison of all simulations: classification of the severity of all ground motion in function of $\mathrm{H}_{2}$ (thickness of liquefiable layer).

\section{Dynamic Response of the Levee}

In this section, the dynamic behavior and the earthquake resistance of the dam embankment (Fig 2) is investigated. This analysis describes the dynamic response of a levee-foundation system and focuses on the liquefaction-induced failure. As in the case of the soil column, parametric studies are conducted in order to explore the influence of the characteristics of the input motion, soil permeability and the thickness of the liquefiable layer on the failure mechanism. In fact, in the past several studies have been proven the crtical role of the influence of foundation soil type and earthquake characteristics [20, 1, 13, 15].

\subsection{Influence of the Drainage Condition}

In the light of this study, three models of different soil permeability are used in order to provide a sensitivity analysis of the liquefaction-induced collapse on the drainage condition between the liquefiable and the non-liquefiable layer. In particular, the values of $K_{s}$ utilized are $1.0 \cdot 10^{-10}, 1.0 \cdot 10 e^{-6}$ and $1.0 \cdot 10^{-5} \mathrm{~m} / \mathrm{s}$. To better evaluate the effect of taking into account different condition of drainage and discuss the dynamic response of the embankment system, the model is subjected to the same ground motion with $a_{b e d, \max }=0.45 \mathrm{~g}$ (Fig.9). In this case, only the model with the minor value of permeability (i.e $K_{s}=1.0 \cdot 10^{-10} \mathrm{~m} / \mathrm{s}$ ) liquefied, while the others conditions do not caused liquefaction. Figures $(10$ and 11) below illustrate the fact that differences appear either in the build up of water pore pressure either in the dissipation 
phase. Figure 10 shows the contours of $r_{u}$ for $K_{s}=1.0 \cdot 10^{-5} \mathrm{~m} / \mathrm{s}$ and $K_{s}=1.0 \cdot 10^{-10} \mathrm{~m} / \mathrm{s}$ during the mainshock and at the end of the shaking, while Figure 11 compares the dissipation of pore water pressure between all the three models. The dissipation of the model with a great value of permeability happens immediately (i.e $K_{s}=1.0 \cdot 10^{-5} \mathrm{~m} / \mathrm{s}$ ), while in the others models the build up of $\Delta p_{w}$ is more extended in time and in the last case it remain even after the motion.

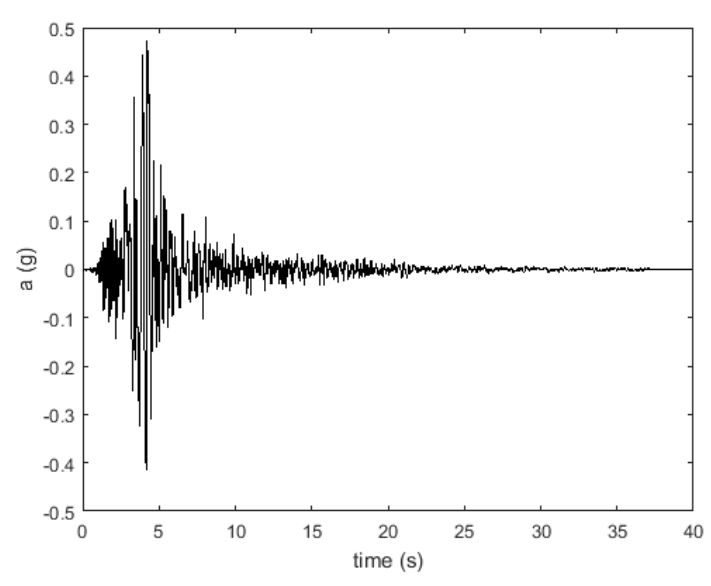

(a) Acceleration of Gilroy.

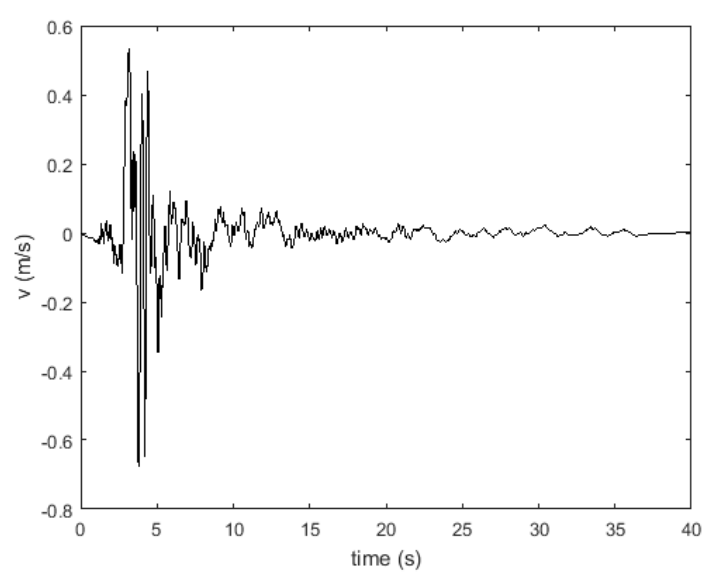

(b) Velocity history of Gilroy.

Figure 9: Input Signal (Gilroy).
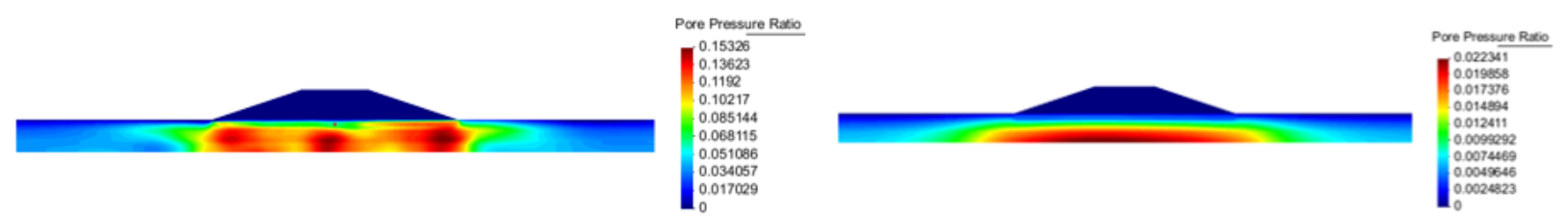

(a) $K_{s}=1.0 \cdot 10^{-5} \mathrm{~m} / \mathrm{s}$ : Mainshock.

(b) $K_{s}=1.0 \cdot 10^{-5} \mathrm{~m} / \mathrm{s}$ : End of the shaking.
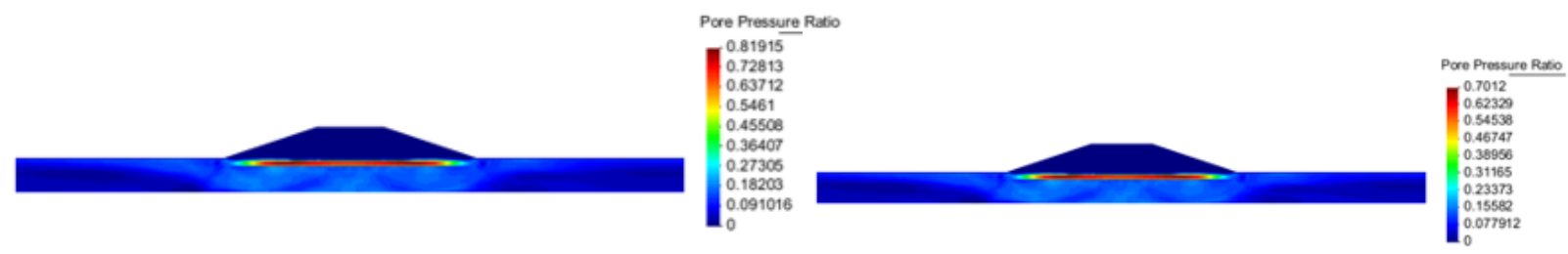

(c) $K_{s}=1.0 \cdot 10^{-10} \mathrm{~m} / \mathrm{s}:$ Mainshock.

(d) $K_{s}=1.0 \cdot 10^{-10} \mathrm{~m} / \mathrm{s}$ : End of the shaking.

Figure 10: Influence of drainage conditions: Excess pore water pressure ratio $\left(r_{u}\right)$. 


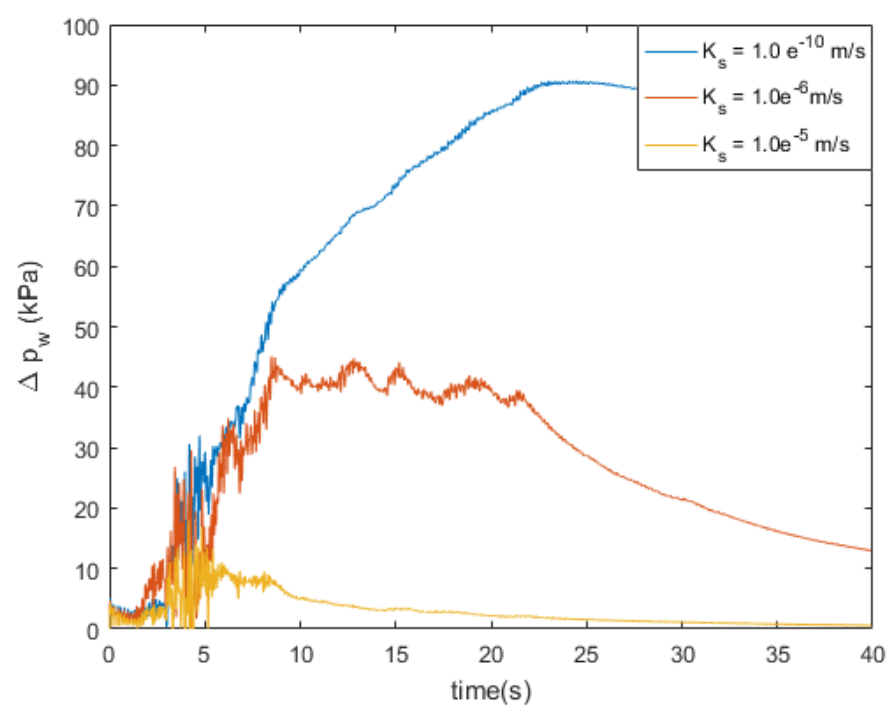

Figure 11: Influence of drainage conditions: Excess pore water pressure $\left(\Delta p_{w}\right)$ evolution during the ground motion.

\subsection{Influence of the thickness of the liquefiable layer}

In this section, the influence of the thickness of the liquefiable layer $\left(\mathrm{H}_{2}\right)$ is assessed through dynamic analyses of two models. The first one is the model presented in Figure 2 and the second one is the same model but with the thickness of the Loose Sand layer equal to $4 \mathrm{~m}$. Firstly, the contours of $r_{u}$ are plotted in Figure 12 for both models during their mainshock and at the end. It is observed that in both cases, excess pore water pressure $\left(\Delta p_{w}\right)$ is generated in the liquefiable layer and liquefaction occured. Figure shows that liquefaction occured for all the two models but the value of $r_{u}$ increases with the thickness of the liquefiable layer. In addition, the area affected by liquefaction is larger for the model with $H_{2}=4 \mathrm{~m}$. The dissipation is slower in the first model and in both models the excess pore water pressure has not dissipated at the end of the earthquake due to the less permeable layers of Clay at the upper and lower part of the liquefied layer. Figures 13 and 14 summarize the deformed shape of vertical displacements the Crest Settlement and the Horizontal Slope displacement at the end of the shaking. The magnitude of displacements increases with the value of the thickness of the liquefiable layer. It is interested to note that not only the value of displacement is increased but also the area and the type of failure is different, in fact displacements are more concentrated in both of the slope. In particular, in the case of $H_{2}=1 \mathrm{~m}$, the failure mode consists in the settle down of the crest of the levee due to the liquefaction of the foundation. Instead, in the case of $\mathrm{H}_{2}=4 \mathrm{~m}$, the mechanism refers mainly to the slopes of the levee. The magnitude of settlement caused by post liquefaction consolidation is directly related to the liquefiable layer thickness. In fact, both Japanese and U.S. researchers (e.g.Hamada and O'Rourke [7]) have identified thickness of the liquefiable layer as a significant parameter affecting the magnitude of lateral spread. 


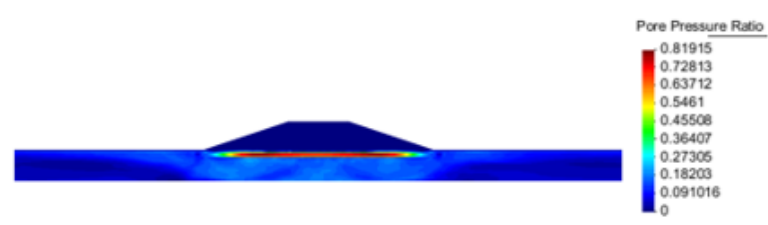

(a) $H_{2}=1 m$ : Mainshock.

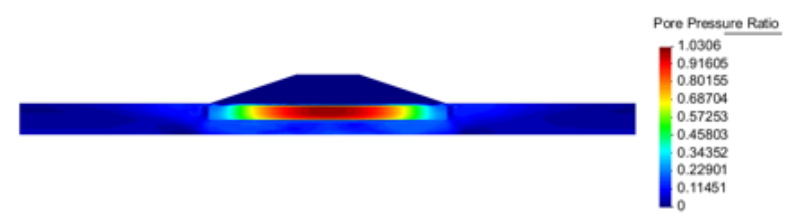

(c) $H_{2}=4 m$ : Mainshock.

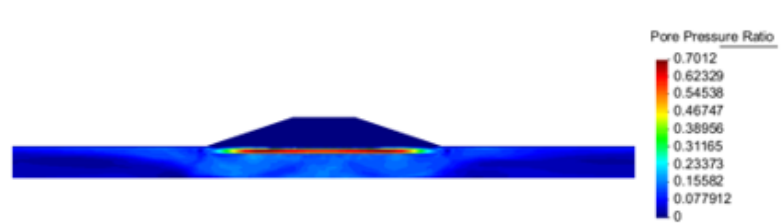

(b) $H_{2}=1 m$ : End of the shaking.

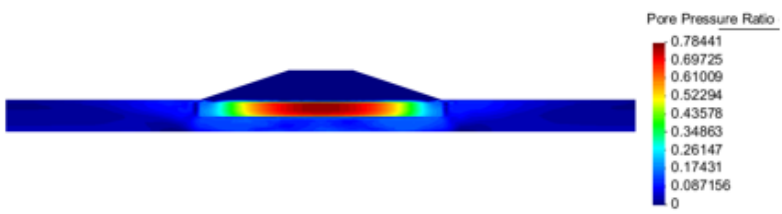

(d) $H_{2}=4 m$ : End of the shaking.

Figure 12: Influence of the thickness of the liquefiable layer $\left(\mathrm{H}_{2}\right)$ : Excess pore water pressure ratio $\left(r_{u}\right)$.

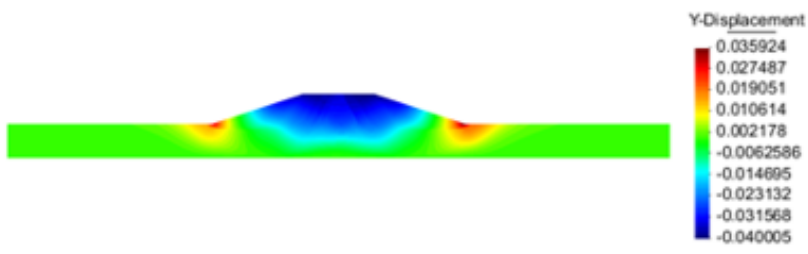

(a) $H_{2}=1 m$.

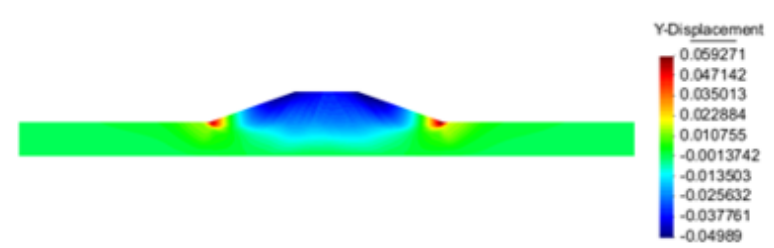

(b) $H_{2}=4 m$.

Figure 13: Influence of the thickness of the liquefiable layer $\left(H_{2}\right)$ : a) $H_{2}=1 \mathrm{~m}$, b) $H_{2}=4 \mathrm{~m}$.

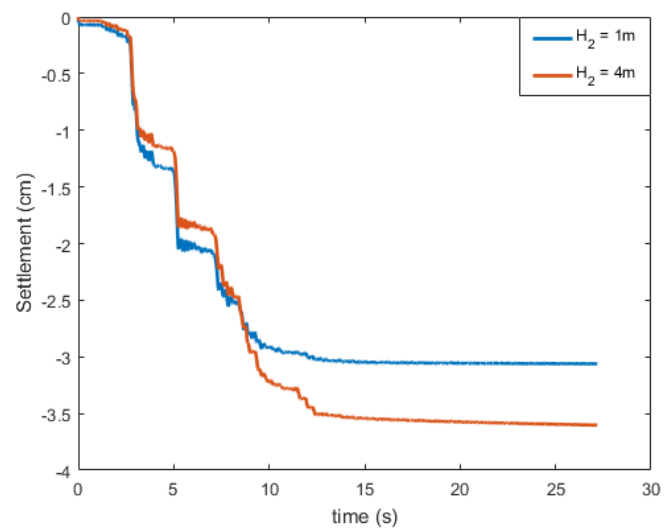

(a) $H_{2}=1 m$.

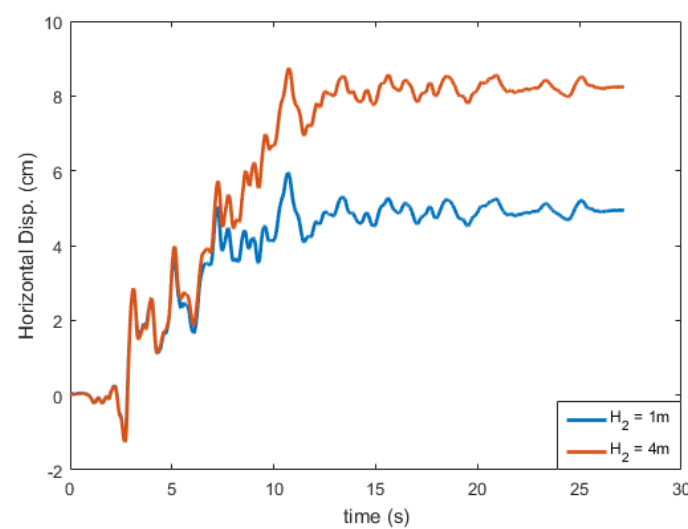

(b) $H_{2}=4 m$.

Figure 14: Influence of the thickness of the liquefiable layer $\left(\mathrm{H}_{2}\right)$ : a) Crest Settlement, b) Horizontal Slope displacement.

\section{Comparison Column-Levee}

\subsection{Dissipation of pore water pressure}

Due to the less permeable Clay layer, the completely dissipation of the pore water pressure $\Delta p_{w}$ in the thin Loose Sand layer is slow. In fact, in the case of the soil column has not yet 
occured at the end of the input motion, while in the case of the levee-foundation, $\Delta p_{w}$ has already begin to dissipate. For this reason, the hydraulic head $h_{w}$ is investigated in order to understand the direction of the dissipation in both cases and figure out what the reasoning is for this.

To determine the direction of water dissipation, the hydraulic head $h_{w}$ is calculated, using the Bernouilli equation (2), where water is supposed to move at velocity $\dot{u}^{w}$. However, as in most soil flow problems, the term $\frac{\left(\dot{u}^{w}\right)^{2}}{2 \cdot g}$ is neglected, because $\dot{u}_{i}^{w}$ is much smaller compared to the pressure and elevation head (smaller than $1 \mathrm{~m} / \mathrm{s}$ ).

$$
h_{w}=\frac{\left(\dot{u}^{w}\right)^{2}}{2 \cdot g}+\frac{p_{w}}{\gamma_{w}}+z
$$

where $p_{w}$ is the pore water pressure, $\gamma_{w}=\rho_{w} \cdot g$ is the water unit weight, $g$ is the gravity acceleration, $z$ is the elevation above a given point.

In order to compare the soil behaviour and the evolution of the pore pressure $\left(\Delta p_{w}\right)$ in the soil column and in the levee-system foundation, both cases are subjected to the same input motion. Intending to evaluate the soil behavior during the dissipation phase (after the end of the ground motion), in the case of the soil column, a dynamic analysis with zero input velocity history $\left(v_{b e d}=0\right)$ follows the end of the earthquake.

Figures 15 and 17 illustrate the contours of hydraulic head $\left(h_{w}\right)$ in the soil column and in the levee-foundation system, respectively, at the end of the ground motion. As shown in Figure 15 , a great part of water dissipates towards the upper part of the column and then, travels to the base of the column. Figure 16 confirms this fact, in fact, it shows that at the end of the ground motion $\left(t_{\text {end }}=25 \mathrm{~s}\right)$, the pore pressure in the middle of the Loose Sand layer (i.e. $10.5 \mathrm{~m}$ below the surface) begin to dissipate. Simultaneously with the dissipation in the liquefiable layer, a slow increase of $\Delta p_{w}$ is observed in the layer of Clay (i.e. $9.5 \mathrm{~m}$ below the surface), which implies that the water tries to dissipate towards the upper part of the column, while at the base (i.e. $13 \mathrm{~m}$ below thw surface) they remain constant. It means that the dissipation is slow as the lower part consists of a less permeable deep Clay layer, hence the dissipation occurs after the shaking. Finally, in Figure 16 the evolution of ground surface settlement is plotted and it is noticed that post-liquefaction settlements continue to increase slowly during the dissipation phase.

Instead, Figure 17 reports the contours of hydraulic head $\left(h_{w}\right)$ in the case of the levee-foundation system. It illustrates the evolution of $h_{w}$ of the thin Loose Sand located buried in the deep stratum of Clay (less permeable) below the levee at the end of the shaking. It shows that as opposed to the soil column, the disspation of the $\Delta p_{w}$ has already started before the end of the shaking. This is due to the fact that, in this case the dissipation of pore water pressure is possible not only towards the upper part but also in the lateral part of the Sand layer as shown in Fig.17. 


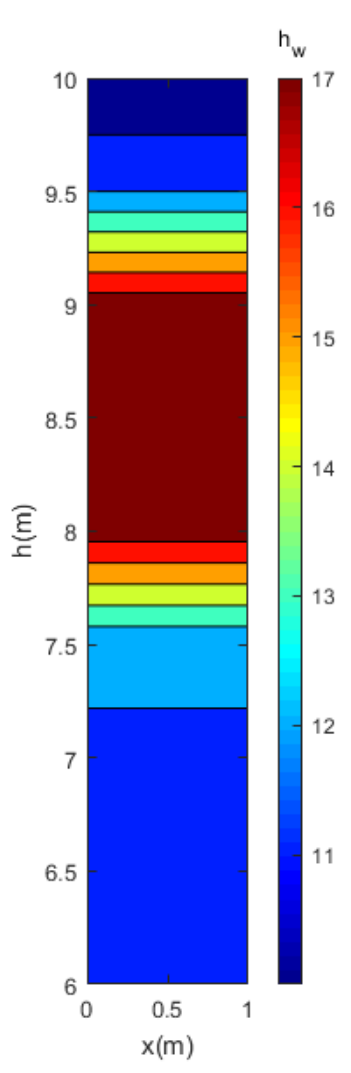

Figure 15: Contours of hydraulic head $\left(h_{w}\right)$ in the soil column at the end of the ground motion.
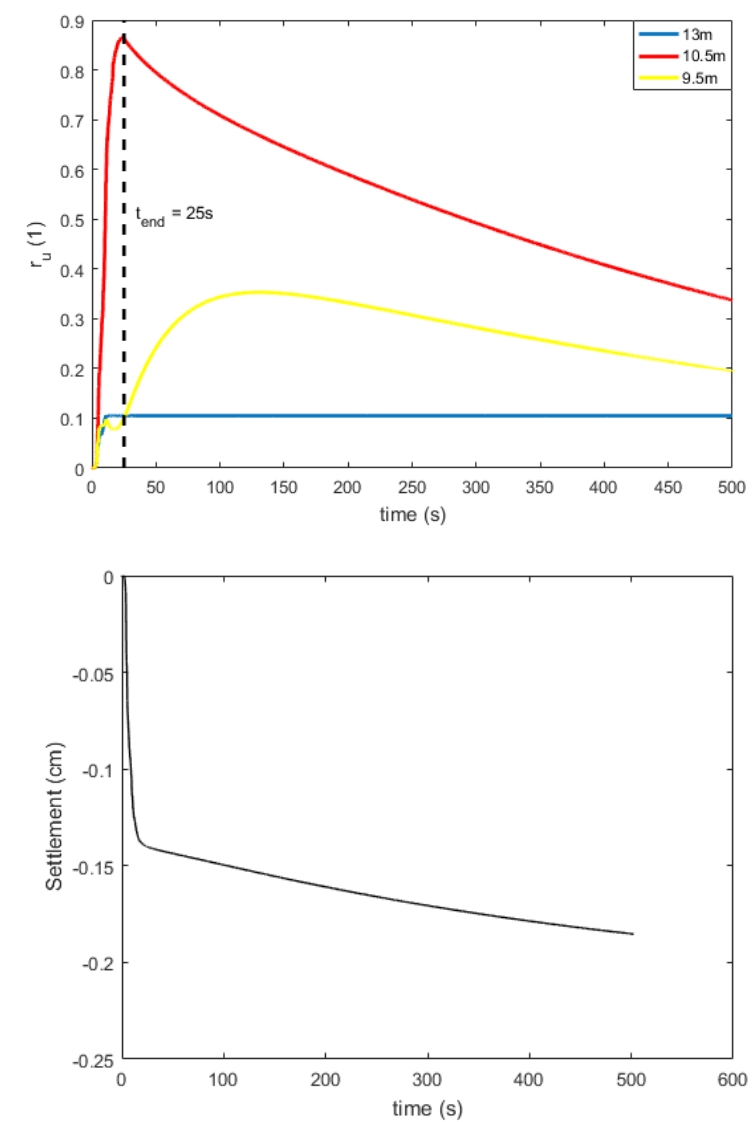

Figure 16: Excess pore water pressure ratio at $13 \mathrm{~m}$, $10.5 \mathrm{~m}$ and $9.5 \mathrm{~m}$ below the surface in the soil column and settlement at the surface of the soil column.

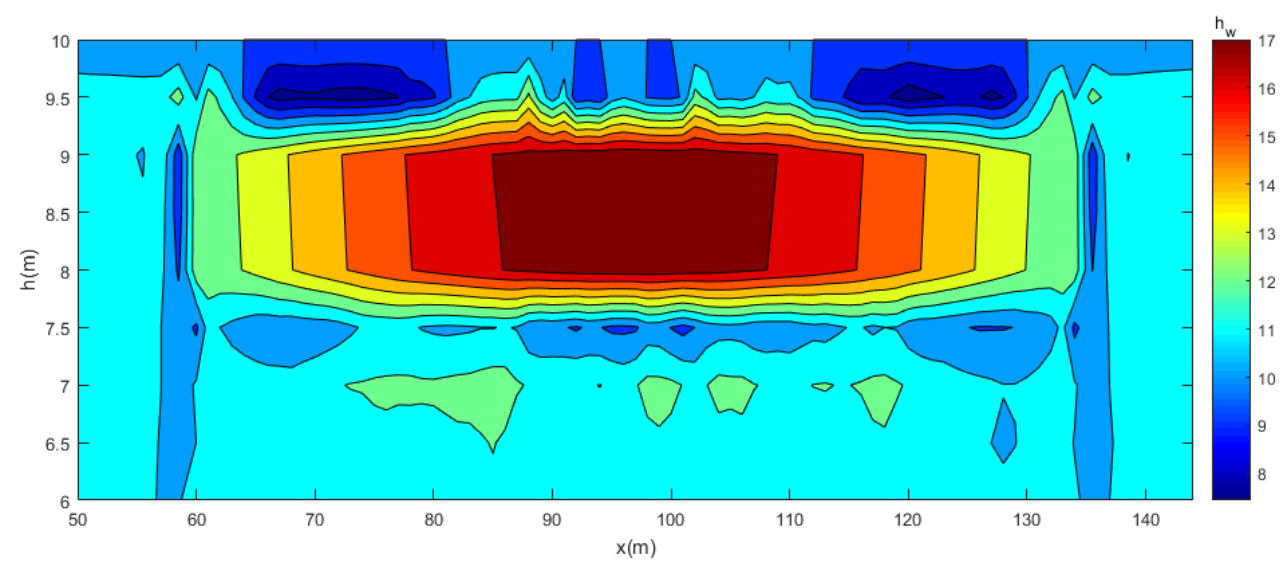

Figure 17: Contours of hydraulic head $\left(h_{w}\right)$ below the levee at the end of the ground motion.

Finally, Figure 18 compares the settlement obtained at the Surface of the soil column and at the Crest of the levee at the end of the input motion. It shows that the trend is the same, in fact the vertical displacement increases almost linearly until $10 \mathrm{~s}$ and then it remains relatively constant for both cases. Although, the value of soil column settlement is not comparable with 
the crest settlement obtained in the embankment system. This is explained by the fact that in the 2D embankment model, the settlement is greater because of the total weigth of the levee above the thin layer of Loose Sand that it is not present in the model of the soil column.

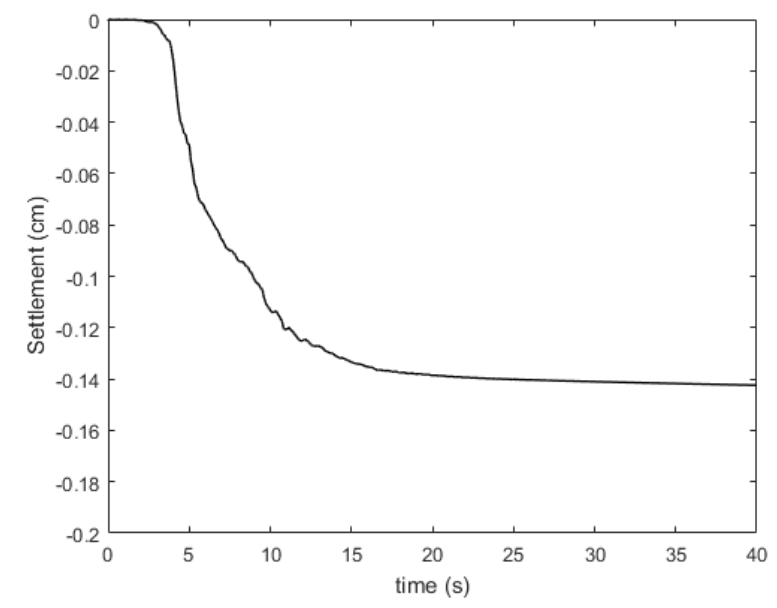

(a)

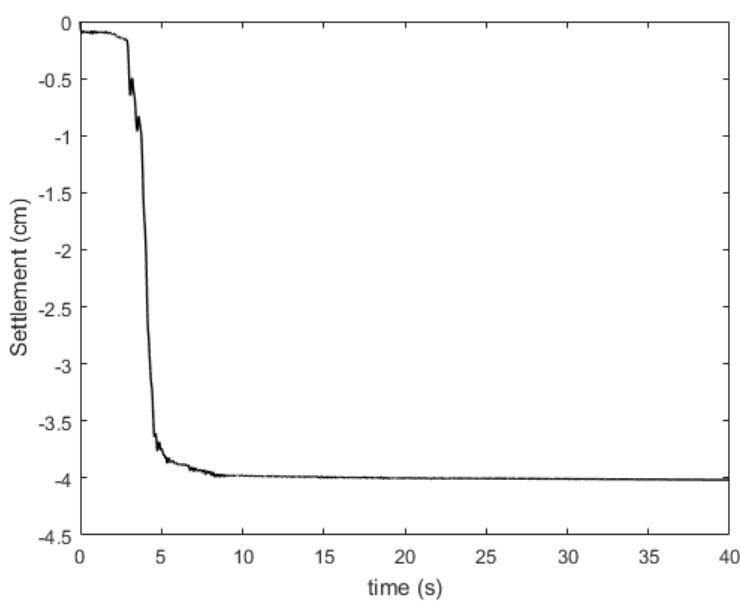

(b)

Figure 18: Comparison of the: a) Soil Column surface settlement and b) Crest settlement of the levee-foundation system at the end of the input motion ( $\mathrm{Rb} 7)$.

\section{Conclusion}

In the past analyses, embankments resting on non-liquefiable foundation soils have not been investigated because it has been supposed that they are rarely damaged during earthquakes. However, more recently it has been reported that several river levees underlain by peat deposits were severely damaged during recents earthquakes. In this study, the behavior of an earth dam founded on a non-liquefiable clay deposit under earthquake loading is evaluated by nonlinear dynamic time history. Through a series of finite element parametric analyses, several aspects were investigated in order to take into account the effects of the liquefaction-induced damage on the dynamic behaviour of the embankment. The main conclusions of this study are the following:

- the drainage conditions at the boundary between the liquefiable and the non-liquefiable layer have a significant influence on the liquefaction behavior of the embankement. For the current levee model, its vulnerability is strongly related to both liquefaction apparition and dissipation of excess pore water pressure. It is showed that maintaining constant the permeability of the liquefiable layer, the lower the permeability value of the nonliquefiable deposit, the higher the induced damage.

- the characteristics of the earthquake and the importance of the seismic hazard are crucial aspects on the dynamic response of the system. It has been showed that the intensity measures of the peak ground acceleration (PGA), peak ground velocity (PGV), mean period $(\mathrm{Tm})$, predominant period (Tp), have an important role on the liquefaction triggering.

- the thickness of the saturated zone influence the generation of the excess pore pressure, the liquefaction apparition and the area of failure. But also a thin saturated layer with a thickness of $1 \mathrm{~m}$ can liquefy during strong base shaking. 
These results are in agreement to the conclusions drawn by Okamura and Yamamoto [19] after centrifuge tests of earth embankments founded on non-liquefiable foundations.

\section{References}

[1] Adalier, K. and Sharp, M. (2004). Embankment dam on liquefiable foundation?dynamic behavior and densification remediation. Journal of geotechnical and geoenvironmental engineering, 130(11):1214-1224.

[2] Cameron, W. and Green, R. (2004). Soil nonlinearity versus frequency effects. In International Workshop on the Uncertainties in Nonlinear Soil Properties and their Impact on Modeling Dynamic Response.

[3] Dafalias, Y. (1986). Bounding surface plasticity. i: Mathematical foundation and hypoplasticity. Journal of Engineering Mechanics, 112(9):966-987.

[4] Elgamal, A., Lu, J., and Forcellini, D. (2009). Mitigation of liquefaction-induced lateral deformation in a sloping stratum: three-dimensional numerical simulation. Journal of geotechnical and geoenvironmental engineering, 135(11):1672-1682.

[5] Elgamal, A., Yang, Z., and Parra, E. (2002). Computational modeling of cyclic mobility and post-liquefaction site response. Soil Dynamics and Earthquake Engineering, 22(4):259-271.

[6] Elgamal, A., Y. Z. and Parra, E., R. A. (2003). Modeling of cyclic mobility in saturated cohesionless soils. International Journal of Plasticity, 19(6):883-905.

[7] Hamada, M. and O'Rourke, T. (1992). Case studies of liquefaction and lifeline performance during past earthquakes, volume 1 japanese case studies. National Center for Earthquake Engineering Research. SUNY at Buffalo, Red Jacket Quadrangle, Buffalo, NY, 14261.

[8] Iervolino, I. and Cornell, C. (2005). Record selection for nonlinear seismic analysis of structures. Earthquake Spectra, 21(3):685-713.

[9] Ishihara, K. (1985). Stability of natural deposits during earthquakes. In Proceedings, 11th International Conference on Soil Mechanics and Foundation Engineering, volume 1, pages 321-376.

[10] Ishihara, K. (1993). Thirty-third rankine lecture: Liquefaction and flow failure during earthquakes. Geotechnique, 43:349-416.

[11] Kawase, H. (2011). Strong motion characteristics and their damage impact to structures during the off pacific coast of tohoku earthquake of march 11, 2011: How extraordinary was this m 9. 0 earthquake. In Proceedings, 4th IASPEI/IAEE International Symposium.

[12] Kramer, S. (1996). Geotechnical earthquake engineering. Pearson Education India.

[13] Lanzo, G. and Pagliaroli, A. (2012). Seismic site effects at near-fault strong-motion stations along the aterno river valley during the $\mathrm{m} w=6.32009$ l'aquila earthquake. Soil Dynamics and Earthquake Engineering, 40:1-14.

[14] Lysmer, J. and Kuhlemeyer, R. (1969). Finite dynamic model for infinite media. Journal of the Engineering Mechanics Division, 95(4):859-878. 
[15] Maharjan, M. and Takahashi, A. (2014). Liquefaction-induced deformation of earthen embankments on non-homogeneous soil deposits under sequential ground motions. Soil Dynamics and Earthquake Engineering, 66:113-124.

[16] Mazzoni, S., M. F. S. M. F. G. et al. (2009). Open system for earthquake engineering simulation user manual version 2.1. 0. Berkeley, CA, University of California, Pacific Earthquake Engineering Center, USA.

[17] Okamura, M. and Hayashi, S. (2014). Damage to river levees by the 2011 off the pacific coast tohoku earthquake and prediction of liquefaction in levees. Safety and Reliability: Methodology and Applications, page 57.

[18] Okamura, M. and Matsuo, O. (2002). Effects of remedial measures for mitigating embankment settlement due to foundation liquefaction. International Journal of Physical Modelling in Geotechnics, 2(2):01-12.

[19] Okamura, M., T. S. and Yamamoto, R. (2013). Seismic stability of embankments subjected to pre-deformation due to foundation consolidation. Soils and Foundations, 53(1):11-22.

[20] Ozutsumi, O., S. S. I. S. T. Y. S. W. and Shimazu, T. (2002). Effective stress analyses of liquefaction-induced deformation in river dikes. Soil Dynamics and Earthquake Engineering, 22(9):1075-1082.

[21] Parra, E. (1996). Numerical modeling of liquefaction and lateral ground deformation including cyclic mobility and dilation response in soil systems. $\mathrm{PhD}$ thesis, [S1: sn].

[22] Prevost, J. (1985). A simple plasticity theory for frictional cohesionless soils. International Journal of Soil Dynamics and Earthquake Engineering, 4(1):9-17.

[23] Ribó, R., P. M., Escolano, E., R. J. G. L., and Rosa, E. (1999). Gid user manual. CIMNE, Barcelona.

[24] Sasaki, Y. (2009). River dike failures during the 1993 kushiro-oki earthquake and the 2003 tokachi-oki earthquake. Earthquake geotechnical case histories for performance-based design-Kokusho (ed), pages 131-157.

[25] Shinozuka, M. and Ohtomo, K. (1989). Spatial severity of liquefaction. In Proceedings of the second US-Japan workshop in liquefaction, large ground deformation and their effects on lifelines, pages 193-206.

[26] Sorrentino, L., Kunnath, S., Monti, G., and Scalora, G. (2008). Seismically induced one-sided rocking response of unreinforced masonry façades. Engineering Structures, 30(8):2140-2153.

[27] Tonni, L., Forcellini, D., Osti, C., and Gottardi, G. (2015). Modelling liquefaction phenomena during the may 2012 emilia-romagna (italy) earthquake.

[28] Yang, Z. and Elgamal, A. (2000). Numerical modeling of earthquake site response including dilation and liquefaction. PhD thesis, Columbia University NY, New York.

[29] Zienkiewicz, O. and Shiomi, T. (1984). Dynamic behaviour of saturated porous media; the generalized biot formulation and its numerical solution. International journal for numerical and analytical methods in geomechanics, 8(1):71-96. 